\title{
Mentorship, Sponsorship, and Professional Networking
}

\author{
Denneal Jamison-McClung
}

\begin{abstract}
Creating an ecosystem of mentorship and sponsorship requires institutional commitment and the collaboration of faculty and administrators from diverse backgrounds. From 2012 to 2018, the UC Davis ADVANCE Mentorship and Networking Initiative (MNI) partnered with the campus leadership to implement several programs and activities to support mentorship, sponsorship, and professional networking for STEM women faculty across career levels. During this award period, pilot programs aimed to provide strong mentorship for newly recruited faculty, including scholars affiliated with the Center for Multicultural Perspectives on Science (CAMPOS) as well as mid-career faculty, with the intention of scaling efforts across campus units. MNI committee projects included piloting "Launch Mentoring Committees" for 43 new faculty, support for faculty-led "New Faculty Network" monthly networking mixers, implementation of the Associate Professor Network listserv, annual co-hosting of the Fall Welcome for Women Faculty, and development of the ADVANCE Scholar Award Distinguished Lecture and Networking Reception. Though all MNI programs and activities were well-received, both faculty mentors and mentees evaluated the Launch Mentoring Committees especially positively. This program emerged as a recommended best practice for engaging new faculty and building a sense of community that crosses disciplinary and intersectional boundaries.
\end{abstract}

Keywords Mentorship - Sponsorship - Faculty development - Academia • Retention and promotion $\cdot$ Career progression $\cdot$ Faculty networking

D. Jamison-McClung $(\bowtie)$

UC Davis Biotechnology Program, University of California, Davis, Davis, USA

e-mail: dsjamison@ucdavis.edu 


\section{Gathering Diverse Institutional Stakeholders and Collecting Baseline Institutional Data}

At the time the interdisciplinary Mentorship and Networking Initiative (MNI) committee was formed, it was clear that disciplinary norms for recruiting, mentoring, and sponsoring new STEM faculty varied widely across campus. To effect institutional transformation in faculty mentoring with an eye toward improving inclusivity, we brought together mid-career and senior STEM faculty with expertise and interest in the topic as well as broad familiarity with existing campus practices and knowledge of "on the ground" challenges. Especially helpful was preliminary data on campus climate and faculty concerns gathered through the 2012-2013 UC Davis Collaborative on Academic Careers in Higher Education (COACHE) survey (Faculty Satisfaction Survey Reports, 2019). Initial MNI working sessions asked, "What are we currently doing? What is working? What seems to be ineffective?" In addressing these questions, we were primarily concerned with the mentoring of new STEM faculty and with the specific challenges faced by women and faculty from underrepresented groups.

Informed by existing literature on faculty mentoring, our discussions examined the potential benefits and drawbacks of common academic mechanisms for new faculty mentoring, such as assigning new faculty members a senior faculty advisor within their home department. A key point of contention that emerged early on was the degree to which we should emphasize structured or formal (e.g., assigned mentors and either peer-led or administration-led mentoring committees) versus lessstructured or informal (e.g., peer-to-peer networking events, informational workshops) approaches for best supporting new STEM faculty in developing robust mentoring relationships and professional networks. Ultimately, MNI moved forward with a suite of options encompassing both approaches that were aligned with UC Davis ADVANCE's overarching goals and had measurable, attainable outcomes.

To link project goals with measurable outcomes, the MNI team collaborated with the internal project evaluators to create a framework based on Kotter's (1995) eight-step theory of organizational change (Fig. 1). In line with the premises of collaborative leadership, MNI activities were championed by specific co-directors and committee members, including both structured/formal pilot programs (Launch Mentoring Committees, ADVANCE Scholar Awards) and less-structured/informal professional networking programs (Welcome Reception for Women Faculty, New Faculty Network, Associate Professor Network). Leveraging internal and external expertise, the MNI team developed and scaled mentorship programs and activities that were modeled on similar efforts that had proven successful on campus and at other research-intensive universities (Bilimoria et al., 2008; Luz, 2011). The origin and development of specific MNI programs and activities are described in the next sections. 


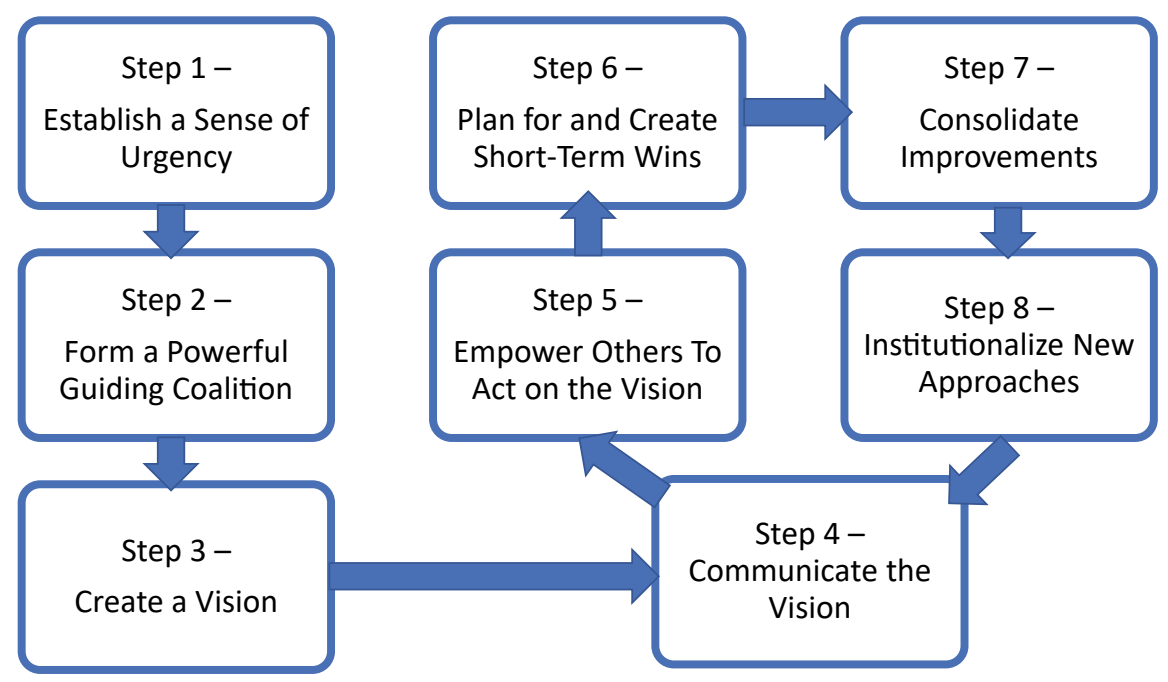

Fig. 1 Kotter's theory of cultural change (1995)

\section{Lessons Learned-Stakeholder Engagement}

To develop scalable, effective models for mentoring, sponsorship, and professional networking within an institution, we learned that it was vital to do the following:

- Engage stakeholders from across STEM disciplines and departmentscolleagues' institutional experiences of mentoring and sponsorship may be more diverse than expected.

- Gather institutional data on faculty experiences of mentoring and networking to identify the main challenges and prioritize limited resources.

- Develop appropriate logic models, such as the theory of change flow chart in Fig. 1, showing the link between program goals and predicted outcomes at the beginning of pilot efforts, in order to set milestones and prevent "mission creep."

- Work with professional program evaluators to develop effective assessment strategies, including participant interviews, to better understand the impact of mentoring pilot programs on new faculty sense of belonging, self-efficacy, and familiarity with campus resources.

- Avoid "reinventing the wheel" when designing solutions to identified challenges:

- Call on internal and external experts to share existing best practices.

- Consider investing resources in scaling up or adapting successful, existing efforts, in addition to creating novel programs and activities. 


\section{Early Career Mentorship and Networking}

MNI pilot programs and activities focused on supporting assistant and associate level faculty colleagues, to help develop effective collegial networks and identify resources needed for career advancement. Newly recruited faculty, such as the CAMPOS Faculty Scholars, were encouraged to participate in early mentorship and networking activities, including the pilot Launch Mentoring Committee program and the New Faculty Network.

\subsection{Launch Mentoring Committees}

For newly recruited assistant professors, emphasis was placed on helping individuals to quickly develop a sense of belonging, become familiar with institutional and disciplinary metrics for success, and make authentic connections to those senior faculty and administrators who had a strong desire to serve as mentors and sponsors. To this end, MNI piloted the structured, committee-based mentoring program called Launch, which was modeled on successful new faculty mentoring programs piloted at Case Western University School of Engineering ("Mentoring + Mentor Fellows Program: Office of Faculty Development: Case Western Reserve University." Office of Faculty Development-Case Western Reserve University) and Michigan State University (Luz, 2011). Typically, Launch mentoring committees were arranged for new faculty in the pilot program during their first few months on campus. Over the course of the award period, 43 new faculty participated in the Launch program, including 19 STEM women faculty.

Launch Mentoring Committees typically included several faculty members:

- Launch Convener-a mid-to-late-career faculty member who invites committee mentors, organize and chair the Launch committee meetings, work closely with the Faculty Mentee to set effective meeting agendas prior to meeting, take and share meeting minutes, and ensure that action items are followed up

- Faculty Mentee-the new faculty member who works closely with the Launch committee Convener to identify potential committee members and prioritize issues to be addressed by the group

- Department Chair - the faculty administrator who is responsible for implementing campus and departmental policies, making teaching assignments, distributing local resources, and conveying a clear sense of departmental merit, promotion, and tenure expectations to the Faculty Mentee

- Internal Senior Faculty Mentor-a mid-to-late-career faculty member who is interested in mentoring a new departmental colleague

- External Senior Faculty Mentor-a mid-to-late-career faculty member who is interested in mentoring across disciplinary lines

- Other Senior Faculty Mentor(s)additional mid-to-late-career faculty members whose perspectives may be useful to new faculty mentees who are conducting 
interdisciplinary research, have joint departmental appointments, or are working on a diverse set of scholarly pursuits.

Launch Mentoring Committees met quarterly for one year, with meetings commencing early in the first year of a new faculty member's arrival on campus. Through our internal evaluation process, we found that most Launch participants (mentors and mentees alike) felt the mentoring activity should start as soon as feasible after the hire; many even suggested that the first Launch meeting should occur before the new colleague arrived on campus. In practice, initial committee formation and meeting scheduling required a few weeks of administrative effort. This timing recommendation, along with the practical challenge of identifying Launch Conveners for each new faculty member, led the MNI committee to recommend that the faculty search committee chairs take on Launch Convener roles as a matter of programmatic practice.

Another recommendation that emerged during pilot evaluation was to extend the Launch program into the second year of the new hire's time on campus. Of the $~ 50 \%$ of participants suggesting extension, both mentors and mentees were equally in favor of the idea. When the Launch program pilot was initiated, there was some discussion about the appropriate time frame for mentoring activity. At the time, we decided that mentoring committees interested in extending their activity beyond one year could elect to do so without formal tracking. In retrospect, we think that institutions adopting the Launch mentoring committee model may want to ask participants to commit to a two-year, quarterly meeting cycle.

To facilitate meeting interactions, the Launch program employed a list of potential discussion questions (Table 1) covering common issues related to setting up and managing a STEM research laboratory, securing funding, and fulfilling teaching and service commitments. In the absence of specific mentoring requests by the new faculty member, the Launch Convener used these questions to guide committee discussions. For example, new faculty may not be aware that departmental teaching expectations change over their career progression. Having the Launch Convener ask questions about pre-tenure teaching loads with the Department Chair present to provide clarity would communicate short- and long-term merit and promotion expectations to the new faculty member while in a neutral, professionally-supportive setting. Faculty mentors from inside and outside of the department could then provide context on whether departmental practices and expectations are based on local, disciplinary tradition or derived from broader campus policies.

To recognize the service work carried out by Launch Conveners and Faculty Mentors, UC Davis ADVANCE worked with campus leadership to send formal letters of commendation that would be appropriate for inclusion in merit and promotion packets. Institutions adopting the Launch Mentoring Committee model should appropriately recognize and reward participating faculty and staff for their contributions to the effort, as well as encourage the participation of an inclusive group of both mid-career and senior faculty. Depending on the level of administrative effort required for an academic unit, a course release or modest stipend may also be appropriate for Launch Conveners. During our pilot program, one Launch Convener 
Table 1 Example launch mentoring committee topics and questions

\begin{tabular}{l|l}
\hline Funding & $\begin{array}{l}\text { Are there grant-writing workshops or other campus } \\
\text { resources for funded research? Who in my department } \\
\text { helps with grant budgets? What is the campus indirect } \\
\text { cost rate for this type of proposal? What is a limited } \\
\text { submission proposal? How can I best use reviewers' } \\
\text { comments to improve proposals? When should I } \\
\text { contact a funding agency program officer with } \\
\text { questions or concerns? }\end{array}$ \\
\hline Research & $\begin{array}{l}\text { Should I continue to collaborate with my postdoctoral } \\
\text { advisor? If I collaborate, will that be seen as a negative } \\
\text { during merit and promotion review? Are there people } \\
\text { on campus in the research area that I should speak } \\
\text { to about collaboration? }\end{array}$ \\
\hline Teaching & $\begin{array}{l}\text { Who makes the teaching assignments? Is there a course } \\
\text { repository for previously used course materials? How } \\
\text { do I use the online course management system? What } \\
\text { types of questions will be on the student evaluations? } \\
\text { Will my course have a TA? Is there a teaching resource } \\
\text { center or other training for new faculty? }\end{array}$ \\
\hline Professional service & $\begin{array}{l}\text { Which requests for service are most beneficial for new } \\
\text { faculty? Least beneficial? When should I decline a } \\
\text { service request? At this career stage, should I consider } \\
\text { external service (e.g., professional societies)? }\end{array}$ \\
\hline Laboratory and personnel management & $\begin{array}{l}\text { I have limited funds-should I hire a postdoc or } \\
\text { support a graduate student? What qualities do I look } \\
\text { for in a new hire? How do professors post available } \\
\text { laboratory technician jobs on campus? Are there } \\
\text { required campus laboratory safety and personnel } \\
\text { manager trainings? }\end{array}$ \\
\hline
\end{tabular}

was often responsible for shepherding three or more committees. Although that was deemed do-able (given administrative support for meeting scheduling and tracking), the team ultimately concluded that Launch Conveners should be responsible for no more than three Launch Mentoring Committees at any given time, to ensure a high-quality experience for new faculty mentees.

Internal evaluation of the project revealed that both mentees $(n=22)$ and mentors $(n=22)$ viewed Launch participation as a valuable experience, with the majority indicating that the most successful aspects of Launch were "getting information and specific resources" (83\% mentees, 95\% mentors) and "feeling welcomed and supported" (78\% mentees, $86 \%$ mentors). The following quotes are representative of the qualitative feedback received from Launch mentees and mentors:

The LAUNCH committee gave me a unique opportunity to connect at the time I needed it the most. I really appreciated the fact that the committee involved professors from my department as well as from other departments. I always received advice from different points of view, which I found particularly invaluable. I remain in touch with most members, and they have become my long-term mentors. - Launch mentee and Assistant Professor Cindy Rubio Gonzalez, Computer Science 
I've been on several Launch Committees. They're an incredible resource for the new faculty. But also, I've learned a lot, and it makes a connection with a new person. Launch Committees are fantastic. - Launch mentor (anonymous)

\section{Lessons Learned-Launch Mentoring Committees}

Based on the results of the pilot Launch Mentoring Committee program described above, we encourage institutions adopting this mentoring model to anticipate the following personnel requirements:

- Identification and training of a sufficient number of Launch Conveners having the time and the expertise needed to establish and manage mentoring committees for all new faculty. As mentioned, one possibility is to assign this role to the faculty search committee chairs responsible for recruitment, as they will already have a good grasp of the new person's research interests, professional strengths, and weaknesses, among other factors. Based on our experience of the administrative effort required per committee, we recommend that each Launch Convener be responsible for no more than three committees at a time. New Launch Conveners should receive guidance on the role from the Vice Provost of Academic Affairs or someone from another central administrative unit responsible for the overall administration of the Launch program.

- Identification of sufficient senior faculty mentors to serve on Launch committees for all new faculty. Small departments, as well as those expecting many new incoming faculty, have occasionally opted to hold "group Launch" meetings, which are shared among two or more new faculty colleagues. By structure, these are not individually tailored mentoring committees but ones that provide general discussion along with helpful resources, in addition to the opportunity for peer-topeer mentoring and networking. Group Launch, we determined, is better than no Launch. However, evaluations of both mentors and mentees indicated a preference for individual Launch committees, when feasible.

- Staff support for tracking and coordination of quarterly Launch committee meetings. It is often challenging to align the schedules of busy faculty members. Doing so may require iterative emails and electronic calendar polls, as well as reserving numerous meeting rooms. Depending on a Launch Convener's professional obligations, they may or may not need assistance with meeting logistics. Central staff support would help to ensure that Launch meetings are not delayed or missed.

\subsection{New Faculty Network (NFN)}

In 2006, an MNI committee member, Magali Billen, started the New Faculty Network (NFN) to serve as an informal social and professional networking group, connecting new faculty members via an email listserv. The decision was made during the UC Davis ADVANCE award period to provide administrative support for the NFN listserv, a NFN annual fall reception, and advertisement of the network to all incoming 
faculty in order to scale participation. The group continues as a faculty-led network of early-to-mid-career faculty who gather for monthly social mixers throughout the academic year. Each year, a few NFN members take the lead in organizing and announcing the monthly events, which are attended by about $15-45$ faculty from across campus disciplines. Events are held at restaurants and public venues off campus.

All NFN members can send announcements to the network; it is straightforward to opt in or opt out of the list, using the institution's open-source mailing list manager, Sympa. Types of social events announced on the listserv have varied with participating faculty interests, including hiking and skiing trips, museum visits, attending performing arts or sporting events, book clubs, salsa dancing, picnics and potlucks, wine tasting, and "happy hour" gatherings. At NFN mixers, the main topics of professional conversation have included local resources to support work-life balance, best practices for teaching and mentoring, navigating the campus merit and promotion system, research funding collaborations, and early career award opportunities.

\section{Lessons Learned-New Faculty Network}

Effective strategies for helping new faculty build professional peer networks may include the following:

- Keep the structure of networking events informal, limiting announcements and maximizing time for peer-to-peer conversations.

- Encourage participation by a diverse group of faculty members, to create an inclusive network with many types of social and professional networking opportunities.

- To ensure continuity over cohorts of incoming faculty, provide Institutional support for informal peer networks, including electronic communication platforms (such as listservs and websites), distribution of related faculty orientation materials, staff support for event announcements and reminders, and resources for at least one annual event.

\section{Professional Networking and Sponsorship}

The MNI committee worked closely with the ADVANCE leadership and management teams, as well as UC Davis Academic Affairs, to develop and scale several activities to encourage peer-to-peer professional networking, promote familiarity with campus faculty professional development resources and efforts to embrace a culture of excellence in mentoring, and recognize the importance of sponsorship across all faculty career stages. Mid-career associate professors were key stakeholders for ADVANCE engagement, having also emerged as a faculty group in need of support on the 2012-2013 UC Davis Collaborative on Academic Careers in Higher Education (COACHE) survey. MNI program development aimed at mid-career faculty included the ADVANCE Scholar Award Distinguished Lecture and Networking Reception, 
and the Associate Professor Network. We also partnered with the campus to cohost an annual reception to welcome women faculty to campus.

Mentorship and sponsorship necessarily have some overlapping characteristics. However, by definition, mentors offer junior colleagues useful advice on careerrelated issues, while sponsors nominate and promote colleagues for career-advancing opportunities and awards, both internally and externally. Having both mentors and sponsors is key for faculty career advancement across demographic groups. Good sponsor-protégé relationships are critical for development of academic leaders within institutions (Huston et al., 2019; Magrane et al., 2018). Recent studies in academic medicine - an area of STEM posing many of the same institutional diversity challenges as university research and teaching-have also highlighted the importance of sponsorship in the career advancement of women and other underrepresented groups along this professional career path (Ayyala et al., 2019; Shakil \& Redberg, 2017).

\subsection{ADVANCE Scholar Awards-An Avenue for Sponsorship}

The ADVANCE Scholar Award was developed to recognize women faculty leaders who were not only excellent researchers but also outstanding mentors. Campus colleagues were asked to nominate mid-career and senior women faculty for the prestigious award, which included a stipend and an invitation to present a distinguished campus lecture in conjunction with a networking reception. This award served as a catalyst for sponsorship of women faculty protégés by senior colleagues. Over the course of the award period, 29 nominations were received and eight ADVANCE Scholar Awards were made. As programs have been institutionalized on campus, this award now falls under the purview of the Office of Diversity, Equity, and Inclusion, with expanded nomination criteria that encompass all "mid-career and senior, ladderranked faculty who will advance gender equity in STEM through their teaching, research or service."

\subsection{Associate Professor Network (APN)}

Given the success of the New Faculty Network and campus survey data indicating that associate professors were the least satisfied with their career trajectories and campus climate, an Associate Professor Network (APN) listserv was developed to facilitate awareness of and access to mentoring and professional development opportunities targeted to mid-career faculty. The Vice Provost for Academic Affairs solicited feedback from associate professors on topics of interest, and the following emerged as top concerns:

- Time management (related to research objectives) 
- Developing and managing collaborative research projects across both internal and external stakeholders

- Preparing merit and promotion dossiers

- Using faculty leaves and accommodations - their impact on advancement

- Strategies for saying "no" to service and other professional requests

- Assessing teaching and course material effectiveness

- Classroom management and encouraging student accountability

- Navigating difficult collegial relationships

- Grant writing and seeking sources of research funding

- Managing laboratory personnel and mentoring graduate students.

The APN continues to be used to announce workshops, networking events, and professional development opportunities on these topics, as well as emerging areas of interest to associate professors. It is not limited to STEM but encompasses associate professors from all fields and disciplines across the campus.

\subsection{Welcome Reception for Women Faculty}

An annual reception for women faculty has been a tradition at UC Davis for many years, originally organized by a center called the Consortium for Women and Research. During the grant award period, the ADVANCE program continued the tradition, co-hosting the Welcome Reception for Women Faculty with the Vice Provost for Academic Affairs and offering a large, interdisciplinary networking opportunity for faculty at all career stages. Attendees at the inaugural event were encouraged to network with faculty from other academic units; faculty new to campus were identifiable via color-coded name tags. A midyear kickoff event was held in February 2014 and was followed by annual events hosted each fall thereafter. Event surveys provided our program with a rich source of local data on the most pressing challenges faced by faculty women, disaggregated by career stage, discipline (STEM and non-STEM) and academic unit.

For the February 2014 event, 117 women faculty attended, representing 14\% of the campus's women full professors, $10 \%$ of women associate professors, and $27 \%$ of women assistant professors. Of these attendees, approximately $80 \%$ responded to the follow-up survey; we learned that $73 \%$ were interested in meeting other women faculty (their primary reason for attendance), while $69 \%$ were "satisfied" or "very satisfied" with the opportunity to expand their professional network. We also provided a list of professional development event topics to determine which would be of most interest to women faculty (more than one choice allowed). The four topics of most interest were Negotiating (64\%), Mentorship (59\%), Grant Funding (53\%), and Work-Life Balance (50\%). An area was provided for write-in topics of interest, and a variety of responses were given, including topics related to lived experiences of diversity and inclusion in the workplace and intersectionality. Examples included: "challenges to communication with colleagues and supervising faculty"; "how to 
convince older white male colleagues that diversity in hiring matters"; "resolving work-related conflicts with male colleagues"; and "specific issues facing women of color."

By providing that large event forum in 2014 for professional networking and discussion of issues affecting women faculty, we were able to identify the topics of most relevance to the campus community. Attendees were drawn from all four academic colleges and four professional schools. By harnessing the collective wisdom of this faculty network, both at the inaugural event and years that followed, we gained a better sense of the mentoring and professional development needs of the community. This invaluable, nuanced data broadly informed the work of UC Davis ADVANCE and the MNI committee.

\section{Lessons Learned-Professional Networking and Sponsorship}

In striving to provide new and mid-career faculty with effective opportunities for professional networking and the development of connections to potential sponsors, consider the following:

- All faculty, but particularly mid-career faculty, are overscheduled and have many professional commitments. Before scheduling networking events or awards symposia, ask key participants (or a subset of the target demographic) which days and times would be most convenient for attendance. Lunchtime events work well for many faculty.

- Be thoughtful in choosing inclusive networking venues that have the event facilities and ground transportation needed for disability access, breastfeeding mothers, small children and caregivers, elderly attendees, service animals, and so on.

- Family care responsibilities disproportionally affect faculty women and can prevent attendance at late-afternoon and early-evening events. Assess whether provision of on-site childcare is possible within institutional policies and resource constraints (if not, this may be an important strategic issue to address). When possible, hold inclusive, family-friendly events that allow attendance of elder parents, partners, children, and others.

\section{Concluding Remarks}

Effective mentorship is necessary for success across the STEM career trajectory. This finding holds true for new faculty, who have ostensibly "made it" past many other obstacles. To navigate the complex cultural expectations and unwritten "rules" of academia, providing a mentor network such as a Launch committee is a must-especially for first-generation STEM professionals and groups historically underrepresented in STEM. Helping senior colleagues identify opportunities for sponsorship of new faculty is also essential for the promotion, retention, and leadership development of these junior colleagues. By providing structured mentorship, sponsorship, and a diverse array of professional development and networking opportunities, academic 
units can set their new faculty hires on the path to tenure and, ultimately, to productive, meaningful engagement in their scholarly communities.

Acknowledgements This chapter summarizes the work and outcomes of the dedicated Mentorship and Networking Initiative committee, whose formal membership over the course of the UC Davis ADVANCE award period included: co-directors JoAnne Engebrecht and Carol Erickson; members Matilda Aidam, Magali Billen, Chen-Nee Chuah, Gitta Coaker, Raissa D’Souza, Lorena Garcia, Lynne Isbell, Deb Niemeier, Binnie Singh, and Jay Stachowicz; and management team members Sophie J. Barbu, Linda Bisson, Kate Blumenthal, Linda Katehi, Denneal Jamison-McClung, Karen McDonald, and Kim Shauman. I appreciate their collective efforts immensely.

The implementation of the programs and activities described here-particularly Launch—also relied on the collegial goodwill and commitment to mentoring of countless staff, faculty, and administrators. Sincere thanks to all UC Davis colleagues working to make our campus a more welcoming and inclusive environment, especially Terry Westover and Lisa Sullivan, the internal evaluators who participated in developing robust logic models and frameworks to identify best practices in mentoring.

Last, but not least, we express deep gratitude to our external advisory board and national colleagues who generously shared their advice and insights on the best programmatic models for faculty mentorship, sponsorship and professional networking: Diana Bilimoria, Carlos CastilloChavez, Olivia Graeve, Brian Nosek, Refugio Rochin, Ivonne Santiago, Abigail Stewart, Caroline S. T. Turner, and Ruth Enid Zambrana.

\section{References}

Ayyala, M. S., Skarupski, K., Bodurtha, J. N., González-Fernández, M., Ishii, L. E., Fivush, B., \& Levine, R. B. (2019). Mentorship is not enough: Exploring sponsorship and its role in career advancement in academic medicine. Academic Medicine, 94(1), 94-100. https://doi.org/10.1097/ ACM.0000000000002398

Bilimoria, D., Joy, S., \& Liang, X. (2008). Breaking barriers and creating inclusiveness: Lessons of organizational transformation to advance women faculty in academic science and engineering. Human Resource Management: Published in Cooperation with the School of Business Administration, the University of Michigan and in Alliance with the Society of Human Resources Management, 47(3), 423-441. https://doi.org/10.1002/hrm.20225

Faculty Satisfaction Survey Reports. (2019). Academic Affairs-UC Davis, Dec. 20, 2019, https:// academicaffairs.ucdavis.edu/faculty-satisfaction-survey-reports-coache

Huston, W. M., Cranfield, C. G., Forbes, S. L., \& Leigh, A. (2019). A sponsorship action plan for increasing diversity in STEMM. Ecology and Evolution, 9, 2340-2345. https://doi.org/10.1002/ ece3.4962

Kotter, J. P. (1995). Leading change: Why transformation efforts fail. Harvard Business Review, March-April 1995, 59-67. https://hbr.org/1995/05/leading-change-why-transformation-effortsfail-2

Luz, C. C. (Ed.) (2011). Faculty mentoring toolkit: A resource for faculty, mentors, and administrators at Michigan State University (NSF ADVANCE Grant \#0811205). East Lansing, MI: Michigan State University. https://www.adapp-advance.msu.edu/files_adapp-advance/content/FacultyMe ntoringToolkit-final.pdf 
Magrane, D. M., Morahan, P. S., Ambrose, S., \& Dannels, S. A. (2018). Institutional matchmakers, sponsors, and strategists: Roles of academic STEM executives in developing the next generation of leaders. Open Journal of Leadership, 7, 168-186. https://doi.org/10.4236/oj1.2018.72010

Mentoring + Mentor Fellows Program: Office of Faculty Development: Case Western Reserve University. (2019). Office of Faculty Development-Case Western Reserve University, July 10, 2019. https://case.edu/facultydevelopment/career/mentoring-mentor-fellows-program

Shakil, S., \& Redberg, R. F. (2017). Gender disparities in sponsorship: How they perpetuate the glass ceiling. JAMA Internal Medicine, 177(4), 582-682. https://doi.org/10.1001/jamainternmed. 2016.9411

Open Access This chapter is licensed under the terms of the Creative Commons Attribution 4.0 International License (http://creativecommons.org/licenses/by/4.0/), which permits use, sharing, adaptation, distribution and reproduction in any medium or format, as long as you give appropriate credit to the original author(s) and the source, provide a link to the Creative Commons license and indicate if changes were made.

The images or other third party material in this chapter are included in the chapter's Creative Commons license, unless indicated otherwise in a credit line to the material. If material is not included in the chapter's Creative Commons license and your intended use is not permitted by statutory regulation or exceeds the permitted use, you will need to obtain permission directly from the copyright holder. 